\title{
Spatial and temporal heterogeneity of Eragrostis curvula in the downstream flood meadow of a regulated river
}

\author{
Pattiyage I.A. Gomes* and Takashi Asaeda \\ Department of Environmental Science and Technology, Saitama University, 255 Shimo-okubo, Sakura-ku, Saitama, 338-8570, Japan
}

Received 26 January 2009; Accepted 18 May 2009

\begin{abstract}
We studied the spatiotemporal trends of Eragrostis curvula (Schrad.) Nees in a flood meadow of a regulated river. The response variables, including the abundance of colonies, colony sizes, flowering spikes, biomass and root structure were checked against a set of environmental variables. These variables included distance from the river, substrate conditions (stony to sandy), soil nutrients (total nitrogen, phosphorous and calcium) and soil moisture. Relationships were evidenced using redundancy analysis. Response variables were found to be distinctive and based on substrate conditions (i.e. stony or sandy). The variables 'distance from the river' and 'soil phosphorous' contributed significantly to the overall variance. Stony habitats were observed to have lower soil nutrient levels and were characterised by monospecific stands of E. curvula, while the high nutrient levels of sandy habitats promoted heterogeneous herbaceous vegetation growth. Primary production, especially belowground, was measured to be significantly higher $(t$-test, $P<0.05)$ in stony habitats. Spatiotemporal trends suggested that, irrespective of the number of colonies, E. curvula demonstrated significant levels of adaptation to micro-environments through biomass allocation and the morphological plasticity of its roots. The study results suggest that river regulation and the subsequent reduction in the frequency of inundation, in addition to the reduction of nutrients and fine sediment supply downstream, give a competitive edge to E. curvula over other herbaceous species.
\end{abstract}

Key words: Eragrostis curvula / redundancy analysis / sandy and stony habitats

\section{Introduction}

River regulation by dams can either increase or decrease downstream vegetation, depending upon the climatic and geological characteristics of a region. Low moisture and low nutrient levels resulting from river regulation are known to inhibit the colonisation of flora (Van Oorschot et al., 1998). However, there have also been reports of enhanced downstream vegetation subsequent to river regulation (Harris et al., 1987; Azami et al., 2004). The stabilisation of downstream soil bars is known to foster the early development of vegetation, generally starting with herbaceous plants (Asaeda et al., 2008) such as Eragrostis curvula (Schrad.) Nees. This fast-spreading species, found in the flood plains of the rivers of Japan, has been listed as an invasive plant in Japan and elsewhere (Matsumoto et al., 2000; USDA, 2008), and the spread of E. curvula has become a threat to many endemic flood-meadow species, such as Aster kantoensis (Matsumoto et al., 2000) and Ixeris tamagawaensis. Eragrostis curvula was introduced

\footnotetext{
*Corresponding author: ishan_gomes@yahoo.com
}

to Japan for its ability to control soil erosion (Nakayama et al., 2007) and many countries use it for this purpose (Colom and Vazzana, 2002). Colonies of E. curvula are known to flourish in a wide range of environmental conditions and often grow to a height of $1 \mathrm{~m}$ (Matsumoto et al., 2000). The centre of a colony generally dies and forms a dead clump as the colony ages (Wan and Sosebee, 2000). The leaves of E. curvula are primarily basal and abundant, with culm leaves of 0.2 to $0.3 \mathrm{~m}$ long, and it has a panicle inflorescence, 0.1 to $0.4 \mathrm{~m}$ long (USDA, 2008). Eragrostis curvula has an extensive fibrous root system, which can exploit depths up to $5 \mathrm{~m}$ and adapt to relatively shallow soils ( 0.2 to $0.5 \mathrm{~m}$ ), as well (USDA, 2008).

The spatial distribution of plants in an area reflects the heterogeneity of the geoenvironmental conditions on which their growth depends (Goodall, 1970). Further, the correlation of species distribution with particular environmental variables has the potential to act as a tool for the explanation of distinctive plant distribution patterns (Goodall, 1970). Plant morphology, along with biomass allocation and distribution, are known to depend upon the spatiotemporal combination of several 
environmental factors. In the case of spatial variables, the substrate plays a major role, as it influences biomass partitioning. For instance, Phragmites japonica growing in riparian areas has been reported to produce a high fraction of root biomass in stony habitats, relative to those growing in sandy habitats (Asaeda et al., 2008). Further, in sandy habitats, $P$. japonica produces a large aboveground biomass with relatively large rhizomes in the belowground system. These differences are found to be dependent upon accessibility to nutrients in the habitats (Asaeda et al., 2008). Seasonal patterns of translocation between aboveand belowground plant compartments have been recognized in several species, including Phragmites australis, Typha angustifolia and Zizania latifolia (Asaeda et al., 2005; Asaeda and Hung, 2007; Sharma et al., 2007). Likewise, Schulze (2000) showed that the distribution of foliage in three-dimensional space depends upon the availability of light.

This study aims to elucidate the spatial and temporal heterogeneity of E. curvula in a flood meadow of the Arakawa River in Kumagaya, Japan. The meadow is characterised by various distinct properties with respect to soil morphology and soil moisture content. The situation is made more complex by the river dynamics, which are influenced by seasonal floods that result in the inundation of part or all of the meadow. Consequently, this meadow provides an ideal setting for a study on spatial and temporal trends, and the results may be useful in the management and/or control of this invasive species. We hypothesized that the substrate (stony or sandy) is significantly related to the spatial heterogeneity of E. curvula. Thus, our objectives were to investigate and answer the following questions: (1) What are the characteristics of the substrate that correlate with and/or influence the spatial abundance (both quantitatively and qualitatively) of E. curvula, and how much variation do these substrates explain? (2) What are the temporal trends of E. curvula in different substrate habitats? We simultaneously assessed the contribution of E. curvula to the flood meadow and the impact of (proposed) sediment flushing from three upstream dams.

\section{Materials and methods}

\section{Study area and overview of studies}

Sampling, field measurements and observations were conducted at a flood meadow of the Arakawa River in Kumagaya, Japan (N $36^{\circ} 08.284^{\prime}$ E $\left.139^{\circ} 21.047^{\prime}\right)$. The Arakawa River is one of the principal rivers flowing through Tokyo Prefecture and it is subject to river regulation by three dams: Futase, Urayama and Kakkaku (for more detailed information of the river and its catchment areas, see Azami et al. (2004) and Asaeda et al. (2008)). This river regulation has resulted in the increased presence of gravel downstream and a reduction in sand accumulation. Also, less frequent submergence of the river's meadows has resulted in more stable plant colonisation.
The climate of the study area is typical of the Asian monsoon zone: it is characterized by warm, humid summers and cold dry winters accompanied by strong seasonal winds (Asaeda et al., 2008).

Figure 1(a) shows the details of the study area. The areas with elevation greater than $3.0 \mathrm{~m}$ were observed to be sandy, whereas areas lower than $3.0 \mathrm{~m}$ in elevation were virtually all stone. However, close to the river and parallel to the river flow, a thick $(25-50 \mathrm{~cm})$ patch of sand on stony substrate was observed. The sand accumulation was a result of the river dynamics, particularly the seasonal flooding and extended periods of withdrawal. The thick herbaceous vegetation around this area traps the suspended sediment (Steiger et al., 2005), as well as the eroded soil from the more highly elevated areas. Furthermore, as the area is on the concave side of the channel, a significant amount of sediment deposition takes place annually. Considering the vegetation, the prima facie evidence was the dominance of E. curvula in the lower elevated $(<3 \mathrm{~m})$ areas. The higher elevated $(>3 \mathrm{~m})$ areas contained mixed vegetation with trees (mainly Robinia pseudoacacia, Salix spp. and Albizia julibrissin) and herbaceous plants.

Water levels obtained from the Kumagaya observatory and through field investigations suggest that the areas $<1 \mathrm{~m}$ are subject to inundation 2 to 4 times per year. The areas with an elevation between 1-2 $\mathrm{m}$ are inundated once a year. During observed floods, the inundation duration was noticed to be no more than a day for the areas $>1 \mathrm{~m}$, and no more than two days for areas $<1 \mathrm{~m}$. The short inundation duration is due to the steep nature of the river. The largest flood recorded in the area occurred on 7 th September 2007 (Asaeda et al., 2008). During this flood, all areas other than those with elevation $>5 \mathrm{~m}$ (not shown) were inundated for 1-5 days.

To assess the spatial heterogeneity of E. curvula, a set of response variables were checked against corresponding environmental variables. This study (Study A) was conducted from late spring to early autumn of 2007 (midJune to early September, i.e. the flowering and growing seasons), a time of year that has witnessed high temperatures and relatively severe rainfalls with subsequent flooding.

To assess the temporal heterogeneity of E. curvula (Study B), colony sampling for biomass was conducted from December 2006 to September 2007 in both an extremely stony habitat and a sandy habitat (Fig. 1(a)). Hereafter, these two habitats will be referred to as Station 1 and Station 2, respectively. The sampling of Station 2 had to be abandoned after September 2007, as the flooding in that month washed away many of the E. curvula colonies, as well as other herbaceous plants. The timing of the sampling made it possible to cover all four seasons, although winter and autumn were just barely covered.

\section{Experiment design, field measurements and sampling}

For Study A, three transects were selected and squares of $5 \mathrm{~m} \times 5 \mathrm{~m}$ were marked (35 Nos.; referred to as 


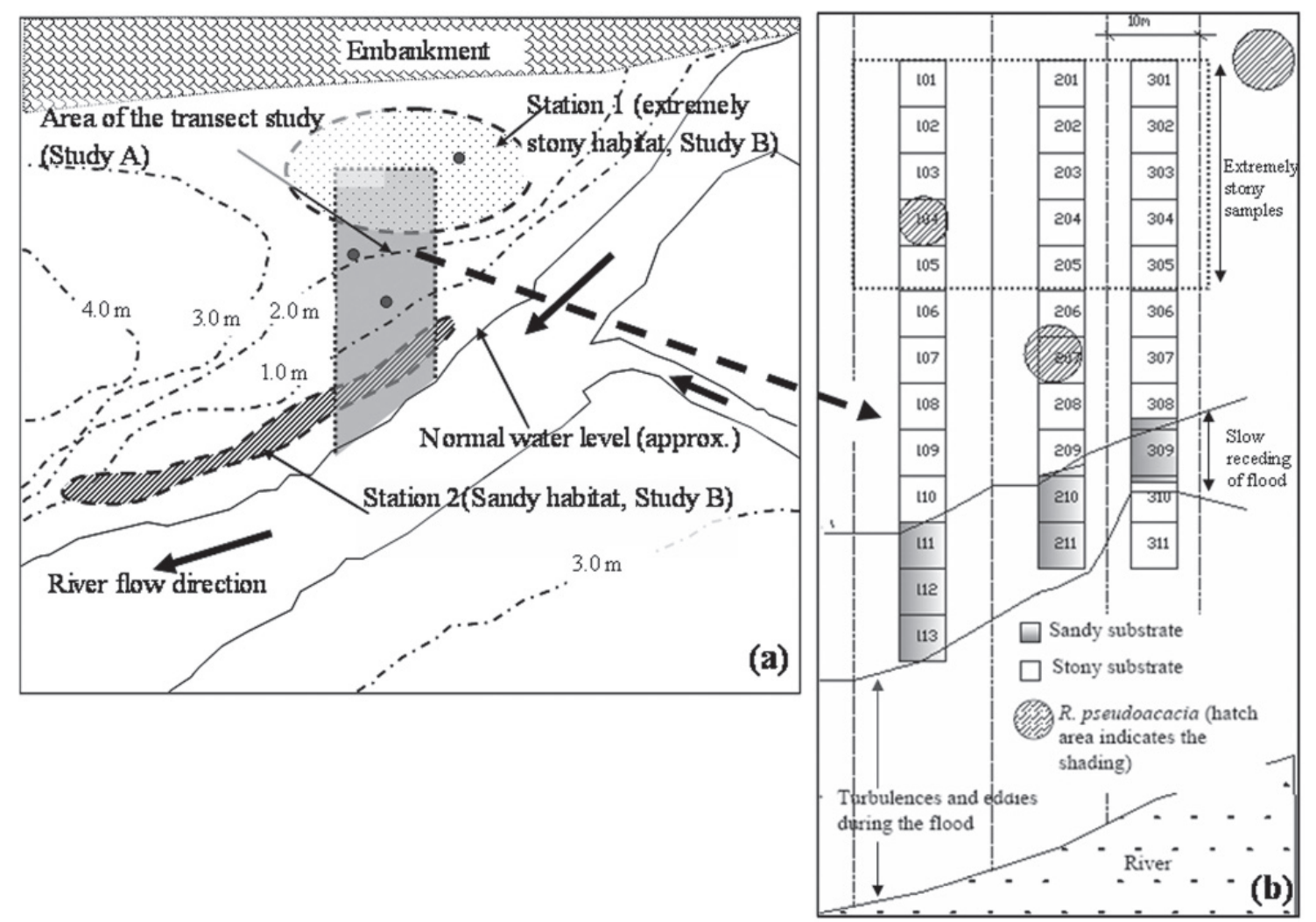

Fig. 1. (a) Aerial view of study area; and (b) arrangement of quadrants in the meadow (drawn to scale). Flood levels are drawn with reference to 15 July 2007 seasonal flood. All stony subdivisions marked, other than extremely stony subdivisions, are moderately stony.

subdivisions), starting from a high elevation and moving towards the riverside where terrestrial plants were found (Fig. 1(a)). Subdivision dimensions were established to easily delineate sandy areas explicitly (in sensu Dutilleul (1993a)). Figure 1(b) illustrates a detailed set up of Study A. The designation of stony areas as either extremely stony or moderately stony was based on preliminary observations. At this stage, intuitive judgements were necessary, as we expected to start sampling for temporal heterogeneity right away. Three categories of colonies were recognised, namely small colonies $(<10 \mathrm{~cm}$ basal perimeter), medium colonies $(10-20 \mathrm{~cm})$ and large colonies $(>20 \mathrm{~cm})$. Small and medium colonies did not have flowering spikes. The absolute number of colonies was determined for each subdivision. Furthermore, populations of other herbaceous species were also counted to evaluate the Shannon-Wiener index (Sigler and Turco, 2002) as an indicator for species richness.

In situ data was collected from each large colony of E. curvula (approx. 3000) in order to derive the average values for a subdivision with respect to the following parameters: maximum height (HMAX), average height (HAV), basal perimeter (PB), maximum perimeter (PMAX) and number of flowering spikes $(\mathrm{F})$. The basal area of a colony was calculated based on the radius of its PB. This was followed by the summation of the individual cross-sectional areas in order to derive the percent of basal cover $(\mathrm{AB})$ for a subdivision. The maximum cover
(AMAX) of E. curvula for a subdivision was assessed by using a $1 \mathrm{~m} \times 1 \mathrm{~m}$ quadrant (consisting of 100 squares). Estimations were carried out for medium and small colonies in each subdivision for all parameters.

A photon sensor (PREDE, Tokyo, Japan; type PAR02) and a data logger (HIOKI Corporation, Ueda, Japan; type 3645) were used to measure the photosynthetic photon flux density (PPFD). Light availability at individual measuring points was indexed using the 'relative PPFD', which is the ratio of PPFD at $5 \mathrm{~cm}$ above ground to that under the open sky (Matsumoto et al., 2000).

Further investigations were completed for particle size analysis, moisture content (MC), and total nitrogen (TN), total phosphorous (TP) and calcium (Ca) in the soil. Soil samplings were carried out in the rhizosphere on days following rainfall, as well as on days with high temperatures and no rainfall. This was done with the anticipation of observing the highest and lowest soil moisture content, resulting in a representative average value. Two samples were taken for particle size analysis (ASTM, 2002), each with a soil volume of $25 \mathrm{~cm} \times 25 \mathrm{~cm} \times 20 \mathrm{~cm}$ (depth). The same process was repeated after the 15 th July 2007 flood. These volumetric dimensions were selected based on the largest particle (cobble) dimensions observed in the subdivisions. The TP, TN and Ca values obtained for each subdivision were multiplied by $\mathrm{P} 2$ (the percentage of particles finer than $2 \mathrm{~mm}$ ), and were then referred to as modified TP, TN and Ca (TPM, TNM, and CaM, respectively). 
A representative sampling of $E$. curvula colonies was conducted from the buffer regions of each subdivision. The selection of sampled colonies was carried out based on colony sizes and the population of an imaginary $1 \mathrm{~m} \times 1 \mathrm{~m}$ square at the centre of each subdivision. Similar representative samplings were carried out for other herbaceous species. Due to practical constraints, herbaceous plant sampling, other than that conducted for E. curvula, was limited to a select group of representative subdivisions $(n=6)$.

For study B, sampling of E. curvula colonies was conducted in $1 \mathrm{~m} \times 1 \mathrm{~m}$ and $2 \mathrm{~m} \times 2 \mathrm{~m}$ quadrants in Stations 1 and 2, respectively (sampling was carried out in duplicate). The quadrant sizes were decided upon based on the random distribution of the number of large colonies in each station (in sensu Goodall (1970)).

\section{Laboratory analysis}

Sampled colonies were washed extensively to remove soil and other foreign matter. Each sample was then ovendried at $71^{\circ} \mathrm{C}$ until no change in weight was observed. Prior to the drying process, samples were sorted into aboveground (shoots) and belowground (roots) portions. Roots were sorted into groups of thick (diameter $>0.1 \mathrm{~mm}$ ) and thin (including root hairs) roots. Total nitrogen analysis on the soil was performed using a Yanoco MT5 CHN Analyzer (Kyoto, Japan). Total phosphorous in the soil was determined using the molybdenum blue colorimetric method (Murphy and Riley, 1962) subsequent to digestion with potassium persulfate (APHA, 1998) in an autoclave $\left(120^{\circ} \mathrm{C}\right.$ for $\left.30 \mathrm{~min}\right)$. Total inorganic $\mathrm{P}$ and organic $\mathrm{P}$ were determined by the ignition method (Kuo, 1996). Samples of ignited $\left(550^{\circ} \mathrm{C}, 1 \mathrm{~h}\right)$ and unignited soil were extracted for $16 \mathrm{~h}$ with $0.5 \mathrm{M} \mathrm{H}_{2} \mathrm{SO}_{4}$. Organic $\mathrm{P}$ was calculated as the difference between inorganic $\mathrm{P}$ in the ignited and unignited samples, while residual $\mathrm{P}$ was calculated as the difference between total soil $\mathrm{P}$ and inorganic $\mathrm{P}$ in the ignited sample. Following the digestion of $1 \mathrm{~g}$ (dry) soil with a mixture of acids in the proportion of $2.5 \mathrm{~mL}$ concentrated $\mathrm{HNO}_{3}$ and $10 \mathrm{~mL}$ concentrated $\mathrm{HCl}$ (USEPA, 3050B), Ca concentration in the soil was measured using flame atomic absorption spectrometry (AA-6300 Shimadzu, Japan) at a wave length of $422.7 \mathrm{~nm}$. Particles finer than $2 \mathrm{~mm}$ were used for TN, TP and Ca analyses (Reith et al., 1987; Asaeda et al., 2008).

\section{Statistical analysis}

CANOCO $4.5^{\circledR}$ was used for relationship building amongst samples (subdivisions), response variables and environmental variables. Redundancy analysis (RDA) was selected, based on the short gradient length of $<4$ (Jongman et al., 1987; Ter Braak and Smilauer, 2002). Scaling was focused on interspecies correlations and species scores were divided by standard deviation. The RDA was obtained by centring the response variables.
Table 1. Ordinal transformation of data used for the supplementary response variable, existence of other perennial herbaceous plants.

\begin{tabular}{lc}
\hline Quantity of organisms & Transformation value \\
\hline $0-6$ & 0 \\
$7-13$ & 1 \\
$14-20$ & 2 \\
$21-27$ & 3 \\
$28-39$ & 4 \\
$\geq 40$ & 5 \\
\hline
\end{tabular}

The conditional and marginal effects of environmental data on species data were assessed using a Monte Carlo permutation test with automatic variable selection. Automatic selection was used to rank the environmental variables on the basis of maximum extra fit. The Monte Carlo permutation test was done using the reduced model from CANOCO for Windows, since the reduced model is better of handling Type I errors in small data sets (Ter Braak and Smilauer, 2002). It should be noted, when two processes are highly autocorrelated, observed Type I errors are significantly high (Clifford et al., 1989; Dutilleul, 1993b). Further, the permutation type was restricted for spatial structure. This is appropriate for line transects and/or samples recorded in equal distances (Ter Braak and Smilauer, 2002). This restriction accounts for the correlations among samples (Ter Braak and Smilauer, 2002). The variable 'other' was used as a supplementary response variable, and we used a simple ordinal transformation (Jongman et al., 1987) to represent the abundance of 'other' perennial herbaceous plants (Table 1).

Preliminary ANOVA testing between extremely stony, moderately stony, stony (including extremely and moderately stony) and sandy samples (Figs. 1(a) and (b)) proved there was no significant difference between stony groups for many response and environmental variables. This made our decision to conduct sampling in extremely stony areas (instead of stony areas; Study B) of little importance. Thus, to assess the significant differences of variables, independent samples $t$-tests were conducted for two groups, sandy and stony, using SPSS version 15 statistical software package (release 13, SPSS INC., Chicago, IL). Values are expressed as mean $\pm \mathrm{SD}$.

\section{Results}

\section{Ordination results}

The RDA triplot is shown in Figure 2. Response and environmental variables based on the first two axes explain $44.7 \%$ of the variance in the response data, $97.4 \%$ of the variance in the fitted response data, the same percentage of variance in the correlations and the class means of the response variables with respect to the environmental variables. Table 2 presents the interset correlations of the environmental variables with axes. Axis 1 is explained 


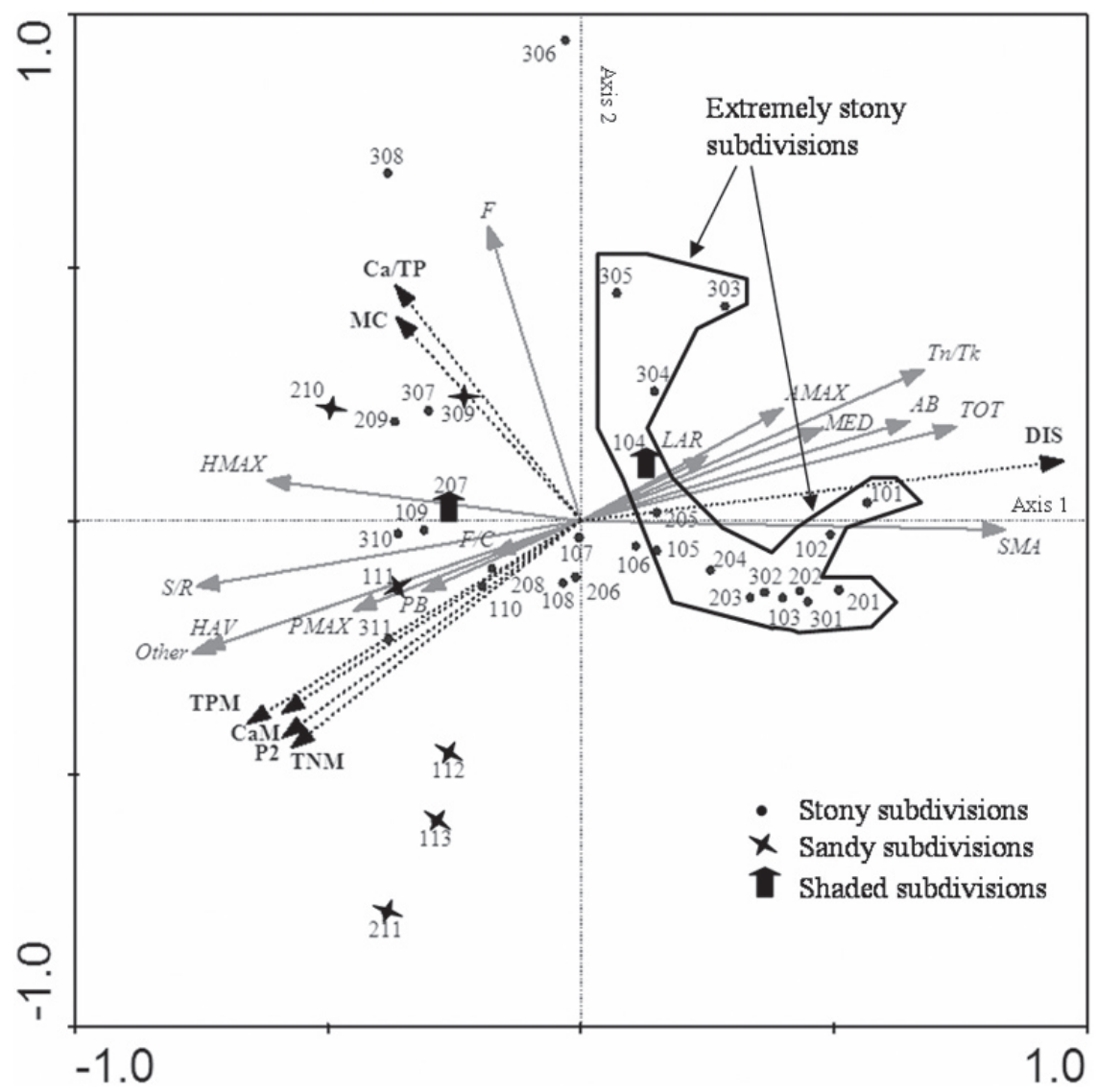

Fig. 2. Tri-plot of the response and environmental variables, and subdivisions. Environmental variables: The distance to the centre of a subdivision from the river (DIS), modified total nitrogen, total phosphorous and calcium in soil (TNM, TPM and CaM); ratio of $\mathrm{Ca}$ and total phosphorous (Ca/TP); soil moisture content (MC); and particle fraction less than $2 \mathrm{~mm}$ (P2). Response variables: Total number of E. curvula colonies (TOT); number of large, medium and small E. curvula colonies (LAR, MED and SMA); percent maximum cover of E. curvula (AMAX); percent basal cover (AB); maximum perimeter of E. curvula (PMAX); perimeter at the bottom of a colony (PB); number of flowering spikes per subdivision $(\mathrm{F})$; and flowering spikes per colony $(\mathrm{F} / \mathrm{C})$; maximum and average height (HMAX and HAV); shoot to root and thin to thick roots ratio (S/R and Tn/Tk); other herbaceous plants (other).

Table 2. Interset correlations of environmental variables with axes.

Abbreviations: soil moisture content (MC), fraction of particles less than $2 \mathrm{~mm}(\mathrm{P} 2)$, modified calcium, total nitrogen and total phosphorous of soil (CaM, TNM and TPM) (arrived at by computing the product of nutrient content in particles less than $2 \mathrm{~mm}\left(\mathrm{mg}^{\mathrm{g}} \mathrm{g}^{-1}\right)$ and the fraction (\%) of particles less than $2 \mathrm{~mm}$ in the rhizosphere), ratio of soil $\mathrm{Ca}$ and total phosphorous $(\mathrm{Ca} / \mathrm{TP})$ and distance from the river (DIS).

\begin{tabular}{lrrrr}
\hline & Axis 1 & \multicolumn{1}{c}{ Axis 2 } & \multicolumn{1}{c}{ Axis 3 } & \multicolumn{1}{c}{ Axis 4 } \\
\hline FR extracted $^{\mathrm{a}}$ & 0.2625 & 0.0588 & 0.0114 & 0.0173 \\
MC & -0.3051 & 0.2487 & -0.0494 & -0.1227 \\
P2 & -0.4917 & -0.2636 & 0.1388 & 0.1293 \\
CaM & -0.4934 & -0.2343 & 0.1130 & 0.1519 \\
TNM & -0.4774 & -0.2763 & 0.1260 & 0.1286 \\
TPM & -0.5505 & -0.2471 & 0.1691 & 0.0577 \\
Ca/TP & -0.3065 & 0.2875 & -0.0300 & 0.2047 \\
DIS & 0.7964 & 0.0730 & 0.0169 & -0.0670 \\
\hline
\end{tabular}

${ }^{\text {a }}$ The fraction of the total variance in the standardized environmental data that is extracted by each species axis.
Table 3. Marginal and conditional effects ranked from the highest explanatory power.

Abbreviations: soil moisture content (MC), fraction of particles less than $2 \mathrm{~mm}$ (P2), modified calcium, total nitrogen and total phosphorous of soil (CaM, TNM and TPM) (arrived at by computing the product of nutrient content in particles less than $2 \mathrm{~mm}\left(\mathrm{mg}^{-\mathrm{g}^{-1}}\right)$ and the fraction (\%) of particles less than $2 \mathrm{~mm}$ in the rhizosphere), ratio of soil $\mathrm{Ca}$ and total phosphorous $(\mathrm{Ca} / \mathrm{TP})$ and distance from the river (DIS).

\begin{tabular}{lcccccr}
\hline & \multicolumn{3}{c}{ Marginal effects } & & \multicolumn{3}{c}{ Conditional effects } \\
\cline { 1 - 3 } Variable & Lambda & Variable & & Lambda A & $P$ & F \\
\hline DIS & 0.26 & DIS & & 0.26 & $0.012^{\mathrm{a}}$ & 11.45 \\
TPM & 0.15 & Ca/TP & & 0.06 & 0.116 & 2.74 \\
P2 & 0.13 & CaM & & 0.05 & 0.166 & 2.92 \\
TNM & 0.13 & TPM & & 0.05 & 0.074 & 2.39 \\
CaM & 0.12 & MC & & 0.03 & 0.236 & 1.45 \\
Ca/TP & 0.08 & TNM & & 0.00 & 0.892 & 0.30 \\
MC & 0.07 & P2 & & 0.01 & 0.780 & 0.22 \\
\hline
\end{tabular}

asignificant $P<0.05$. 


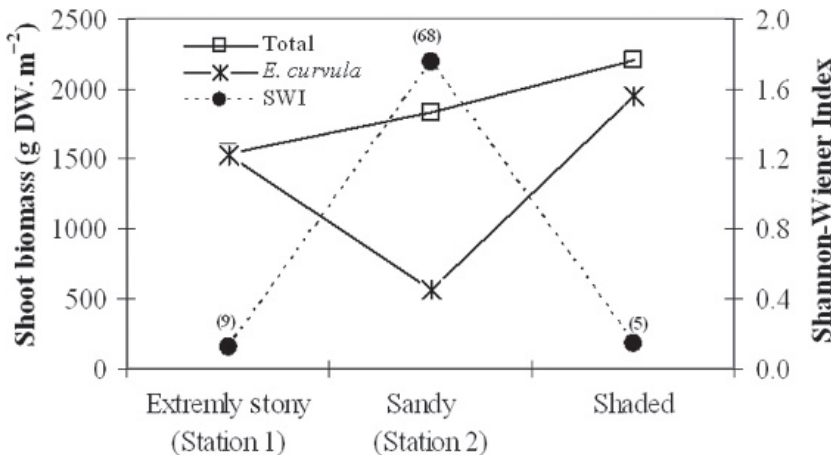

Fig. 3. Shoot biomass of all herbaceous species (Total) and E. curvula together with Shannon-Wiener index (SWI) for extremely stony, sandy and shaded subdivisions. The parentheses give number of other herbaceous species per subdivision.

by the distance (DIS) from the river to a subdivision, whereas Axis 2 is explained by the ratio $\mathrm{Ca} / \mathrm{TP}$. The marginal and conditional effects of the environmental variables were ranked, starting from the highest explanatory power, and are shown in Table 3 . The variables distance from the river (DIS) and amount of modified total phosphorous in the soil (TPM) were found to be significant (Monte Carlo, $P<0.05$ and $P<0.1$, respectively), followed by the ratio of $\mathrm{Ca} / \mathrm{TP}$ and modified $\mathrm{Ca}$ in the soil (CaM) (Monte Carlo, $P<0.2$ ).

Stony subdivisions appeared to become polarised on the right side of the first axis. This was particularly evident in the extremely stony subdivisions (which fell within Station 1 of Study B). In addition, all of the sandy subdivisions were located on the left side of the first axis.

Separating the subdivisions into sandy and stony using Axis 2 allowed us to see two sets of growth characteristics for E. curvula, based on the substrate, and proved one hypothesis to be true. There was a large convergence of 15 of the stony subdivisions (Fig. 2), which were also identified as being the initial subdivisions for transects. In addition, the remaining stony subdivisions were grouped near the extremely stony subdivisions. The extremely stony samples were polarised and showed a relatively high abundance of E. curvula over the means of the response variables for small colonies (SMA), medium colonies (MED), large colonies (LAR), total number of colonies (TOT), thin to thick roots ratio $(\mathrm{Tn} / \mathrm{Tk})$ and the percentage of maximum cover by E. curvula (AMAX). In contrast, they produced less than average values for shoot to root ratio $(\mathrm{S} / \mathrm{R})$, basal perimeter $(\mathrm{PB})$, maximum perimeter (PMAX), average height of colonies (HAV), maximum height of colonies (HMAX) and number of flowering spikes per large colony $(\mathrm{F} / \mathrm{C})$. Relatively high cover (AMAX) proved that E. curvula dominated the respective subdivisions. The supplementary variable 'other' was positioned in such a way as to make the abundance of other species in these samples far lower than the average, while the opposite was true for sandy subdivisions.

An obvious relationship exists, which demonstrates a strong correlation between the total number of colonies
Table 4. Modified ${ }^{\mathrm{a}}$ values for total nitrogen (TN), total phosphorus (TP), organic phosphorous and residual phosphorous for extremely stony and sandy habitats (Stations 1 and 2). Parentheses contain standard deviation. a Arrived at by computing the product of nutrient content in particles less than $2 \mathrm{~mm}\left(\mathrm{mg} . \mathrm{g}^{-1}\right)$ and the fraction (\%) of particles less than $2 \mathrm{~mm}$ in the rhizosphere.

\begin{tabular}{llr}
\hline Habitat & \multicolumn{1}{c}{ Station 1 } & Station 2 \\
\hline TN & $0.785(0.287)$ & $25.193(1.549)$ \\
TP & $0.431(0.015)$ & $13.144(1.071)$ \\
$\quad$ Inorganic P & $0.030(0.019)$ & $1.771(0.052)$ \\
$\quad$ Organic P & $0.073(0.016)$ & $2.351(0.179)$ \\
$\quad$ Residual P & $0.326(0.010)$ & $9.023(1.198)$ \\
Particle fraction & $1.57(0.05)$ & $43.81(3.57)$ \\
less than 2 mm & & \\
\hline
\end{tabular}

(TOT) and the distance from the river (DIS). The total number of colonies (TOT) showed a strong inverse correlation with the nutrient variables (TNM and TPM), and also with particle fractions less than $2 \mathrm{~mm}(\mathrm{P} 2)$. This indicates that abundance is high when nutrient levels are low and there are fewer fine particles. The same trend is evident in the case of modified calcium (Ca) concentrations in the soil (CaM). Further, stony subdivisions (especially extremely stony subdivisions; Fig. 2) had below average levels of TNM, TPM and CaM. Furthermore, TNM, TPM, CaM and the fraction of particles $<2 \mathrm{~mm}(\mathrm{P} 2)$ of stony subdivisions had significantly lower values ( $t$-test, $P<0.05)$ than those of sandy subdivisions.

\section{Species richness, biomass production and soil nutrients}

Figure 3 shows the shoot biomass of herbaceous species together with species richness (represented by the Shannon-Wiener index) for randomly selected extremely stony, sandy and shaded subdivisions. Shaded subdivisions showed the highest biomass production, followed by sandy; whereas extremely stony subdivisions showed the lowest. However, only $30 \%$ of shoot production in the sandy subdivisions was attributed to E. curvula. On the other hand, almost $90 \%$ of shoot biomass was attributed to E. curvula in the shaded subdivisions, and almost $100 \%$ in the extremely stony subdivisions. Species richness was noticeably low for extremely stony and shaded samples; whereas sandy samples were higher. Sandy samples contained Artemisia capillaris, A. princeps, P. japonica, Lespedeza cuneata, Equisetum palustre, Polygonum nodosum and $P$. hydropiper in greater numbers. A few I. tamagawaensis were found in stony habitats.

Table 4 presents the modified values of TN, TP, inorganic $\mathrm{P}$, organic $\mathrm{P}$ and residual $\mathrm{P}$ in the soil of Stations 1 and 2 . The modified values were found to be significantly different ( $t$-test, $P<0.05$ ) for Stations 1 and 2 . Even the values based on fractions of particles less than $2 \mathrm{~mm}$ (i.e. unmodified values) suggest that Station 2 has 

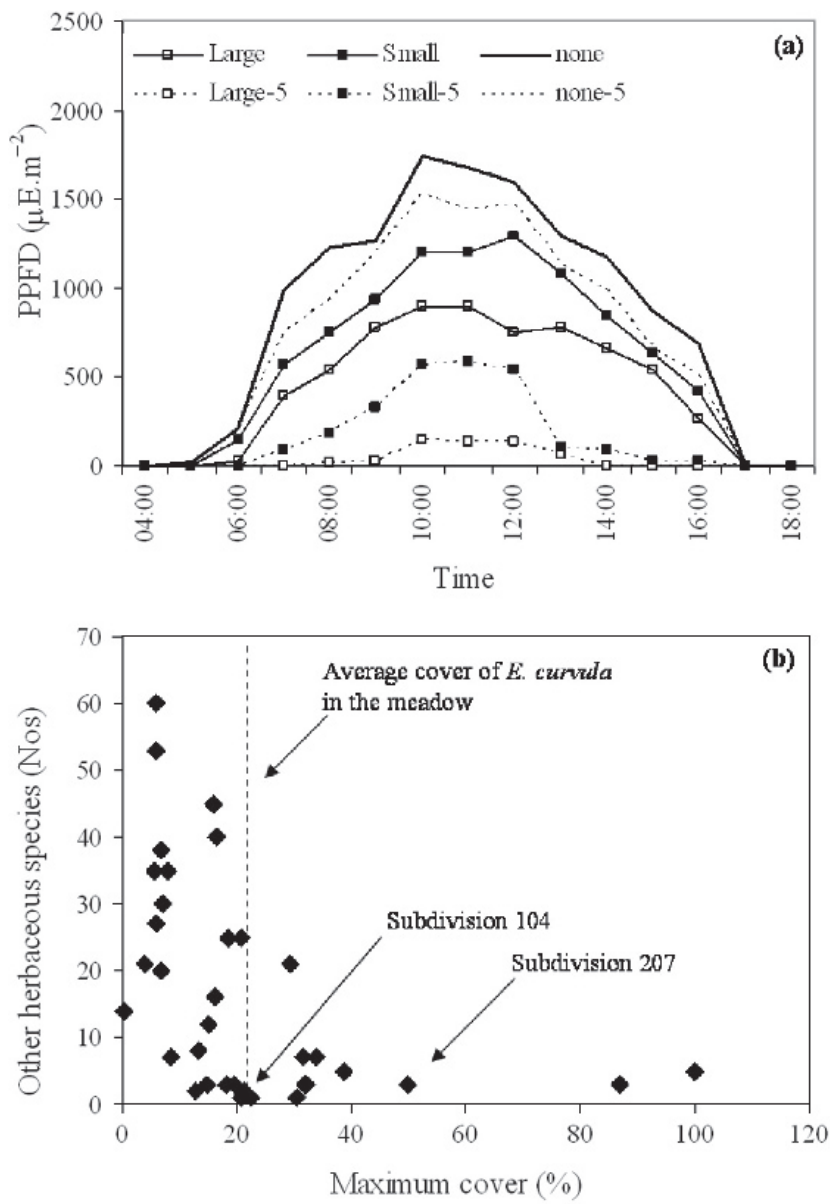

Fig. 4. (a) Variation of irradiance of samples subject to shading and no shading by $R$. pseudoacacia. Photosynthetic photon flux density (PPFD) at the canopy height of E. curvula (1.5 m from surface) is shown in solid lines, open space (no shading by trees) - no marker, shaded by $R$. pseudoacacia with marker (small tree (subdivision 104)-filled marker; large tree (subdivision 207) - hollow marker). PPFD at $5 \mathrm{~cm}$ from the earth's surface shown in broken lines. (b) Relationship between populations of other herbaceous plants and maximum cover of E. curvula.

higher nutrient levels than Station 1. Station 2 contained high levels of nutrients and was a habitat for several types of herbaceous plants. Thus, intense competition between species inhibited E. curvula production. On the other hand, Station 1 contained fewer nutrients and had very few other herbaceous species.

\section{Influence of the distribution of E. curvula on light availability and abundance of other herbaceous species}

Figure 4(a) shows the PPFD measured at the canopy height of E. curvula (approx. $150 \mathrm{~cm}$ from the earth) and at a height of $5 \mathrm{~cm}$ from the earth for an open subdivision (i.e. no R. pseudoacacia; subdivision 204 with AMAX of $22 \%$ was used) and subdivisions with trees (sample 207:
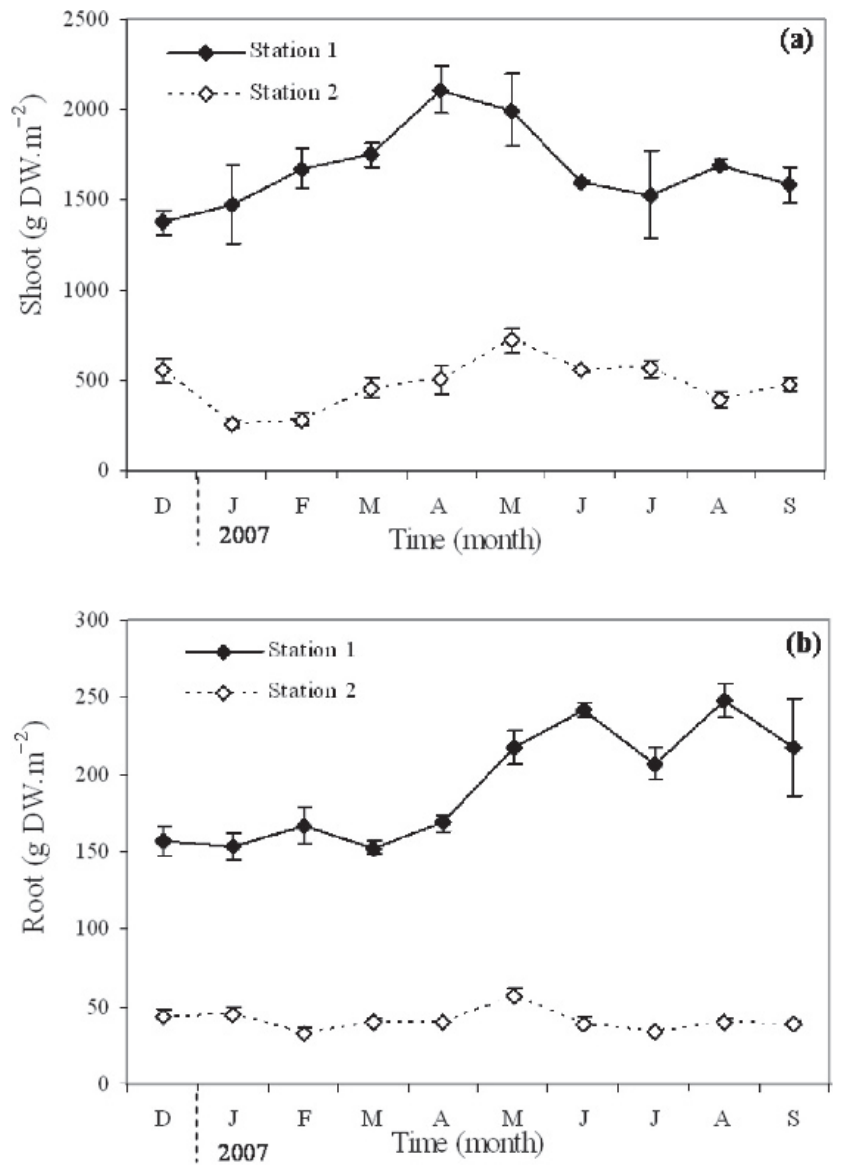

Fig. 5. Temporal variations of (a) shoots; and (b) roots biomass in $\mathrm{g}$ dry weight (g DW) per $\mathrm{m}^{2}$ of Station 1 and Station 2.

large tree; 104: small tree). It should be noted that the meadow's average AMAX was 22\%. Relative PPFD of open subdivisions was observed to be between 40-95\%. Meanwhile, relative PPFD of subdivision with a small tree and the subdivision with a large tree were observed to be between $0-35 \%$ and $0-8 \%$, respectively. Figure 4(b) shows the relationship between the maximum cover of E. curvula (AMAX) and the number of other herbaceous species. It seems that as the E. curvula cover increased, other herbaceous populations declined.

\section{Temporal variation of biomass production and biomass partitioning of E. curvula}

Figures 5(a) and 5(b) illustrate temporal variations of shoot and root biomass per $\mathrm{m}^{2}$ of Stations 1 and 2. The shoot and root production per unit area was obviously higher in stony habitats (Station 1) than in sandy habitats (Station 2). The shoot biomass per unit area was approximately 3-6 times greater in Station 1 than in Station 2, and the root biomass per unit area was approximately 4-7 times greater in Station 1 than in Station 2. However, with respect to biomass production per colony (largest 4 colonies in each month's sampling (Figs. 6(a) and 6(b)), Station 1 only had higher shoot biomass in January 

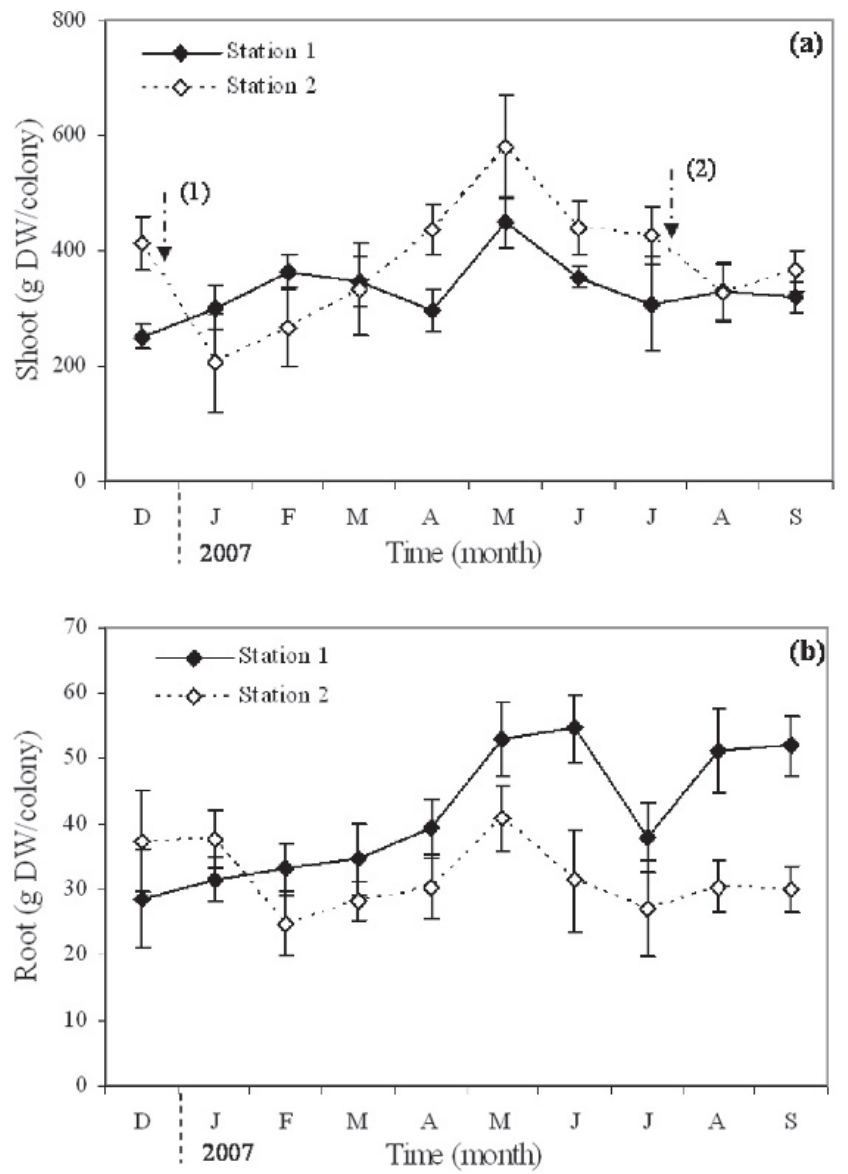

Fig. 6. Temporal variations of (a) shoots; and (b) roots biomass in g dry weight (g DW) per colony $\left(n=4\right.$, largest $\left.4^{\#}\right)$ for Station 1 and Station 2. Vertical arrows (1) and (2) indicate flooding on 17th December 2006 and 15th July 2007. (\#: Large colonies (i.e. basal perimeter $>20 \mathrm{~cm}$ ) obtained by monthly sampling conducted for quadrant basis analysis, such as in Fig. 5. Large colonies, harvested each month, were not less than 4.)

and February. The shoot biomass values reported for January and August were noticeably low relative to the previous month's values for Station 2.

Temporal variations suggest that the difference in shoot biomass per colony between Stations 1 and 2 is statistically insignificant ( $t$-test, $P>0.05)$. In contrast, root biomass per colony in Station 1 was higher throughout the study period, except in December and January. For the months of May, June, August and September, the difference in root biomass per colony was found to be statistically significant ( $t$-test, $P<0.05$ ).

\section{Discussion}

\section{Variation of environmental and response variables}

Sandy and stony (especially extremely stony) subdivisions showed opposite trends with respect to soil nutrients (TNM, TPM and CaM) and particle size (P2). High TNM and TPM values in sandy subdivisions can be explained by the seasonal flooding and also high levels of $\mathrm{P} 2$, which provided a larger surface area in the soil. The seasonal flooding (2-4 times per year) removed litter from, and carried litter to, the submerged areas. However, as per the observations made in the area, the flooding created distinct effects in the meadow, based on the receding duration, which was probably influenced by slope differences in the meadow. The sandy areas under consideration were subject to relatively high inundation periods and subsequently slow flood receding speeds (Fig. 1(b)). This led to a bulk accumulation of litter of approximately $0.82 \mathrm{~kg} . \mathrm{m}^{-2}$ per flood event.

Nutrient deposition during floods is important for riparian areas (Brunet and Astin, 2000; Steiger and Gurnell, 2002; Asaeda and Rajapakse, 2008). Rainfall and night-time dew formation can serve to mineralise the litter (Dillaha et al., 1989; Austin et al., 2004). It is likely that the low elevation of sandy areas (just above the river water level) makes the substrate relatively wet throughout the year, thus promoting subsequent mineralization.

Furthermore, stony subdivisions contain less than average levels of CaM, which leads to lower concentrations of biologically available $\mathrm{P}$. The reduced availability of $\mathrm{Ca}$ can be explained by leaching, which is the result of $\mathrm{Ca}$ reacting with $\mathrm{H}^{+}$produced through nitrification (Mengel and Kirkby, 2001). The final product is drained off during the rainy season. Soils are prone to strong fixation of phosphate by way of adsorption to sesquioxides and clay minerals, thus availability of high concentrations of $\mathrm{Ca}$ is of the utmost importance to eliminate the low $\mathrm{pH}$ conditions that cause strong phosphate fixation (Mengel and Kirkby, 2001).

When the nutrients are diminished, as in stony subdivisions, the belowground biomass of the colonies, contain a relatively large proportion of thin roots, as a means of increasing root surface area per unit volume of soil. Low HAV and HMAX explain why the colonies are less healthy and less productive, since the $\mathrm{F} / \mathrm{C}$ is also low. Considering the lower levels of production and species richness in stony subdivisions (Fig. 3), it can be stated that species compete for soil resources (Osem et al., 2002) in this relatively unproductive environment. On the other hand, due to the high availability of nutrients in sandy subdivisions, production is high, thus plants in these areas compete for light (Osem et al., 2002). This seems to be the reason E. curvula showed exceptionally high values for $\mathrm{HAV}$, and to some extent, HMAX in sandy subdivisions.

Thus, areas where nutrients are scarce are extremely unfavourable for plant growth. However, these areas yielded the highest abundance of E. curvula (Fig. 3). Furthermore, E. curvula belongs to the monocotyledons species (USDA, 2008); therefore, it contains less $\mathrm{Ca}$ and is also less susceptible to Ca deficiency (Loneragan and Snowball, 1969; Islam et al., 1987).

\section{The effect of soil moisture on E. curvula}

The ordination diagram (Fig. 2) indicates that the total population of E. curvula (TOT) has no relationship 
with soil moisture (MC), as these two variables are almost perpendicular to each other. Furthermore, there was not a significant difference with respect to MC between sandy and stony samples $(t$-test, $P>0.05)$. It should be noted that many of the stony subdivisions were located about $2 \mathrm{~m}$ above the river water level. In addition, the fine particle fraction was very low. Large sediments and their relatively large voids produce higher evaporation rates of sediment moisture, while fine sediments curtail its flux (Asaeda and $\mathrm{Ca}, 1993)$. Thus, there needs to be some contribution from $E$. curvula to make the difference in MC insignificant (strictly speaking, this is the moisture content in the rhizosphere). The colonies in the stony subdivisions contained a noticeable dead clump in their centres. This hollow crown characteristic of many perennial tussocks is a natural consequence of development morphology, and not a symptom of plant stress or disturbance (Gatsuk et al., 1980; Wan and Sosebee, 2000). Furthermore, the central dead clump preserves the scarce soil moisture (Wan and Sosebee, 2000). Thus, the dead centres appear to be a major survival strategy adopted by $E$. curvula in the stony subdivisions. This soil moisture preservation resulted in an observable level of wet soil in the rhizospheric zone of the stony subdivisions.

\section{Seed bank and seed dispersal}

The total flowering spikes of a subdivision (F) did not show a preference for substrate or nutrients, as the arrow for $\mathrm{F}$ is positioned symmetrically over sandy and stony subdivisions (Fig. 2). This was further proven by a $t$-test $(P>0.05)$. However, flowering spikes per colony $(\mathrm{F} / \mathrm{C})$ of a subdivision clearly show a higher abundance in sandy habitats. This was found to be significantly higher ( $t$-test, $P<0.05)$, demonstrating that while the number of E. curvula colonies is less than the average in sandy subdivisions, its seed bank per colony is large. Halvorson and Guertin (2003) reported E. curvula develops an increased proportion of shoots that produce panicles when the soil nitrogen content is high. Thus, high levels of $\mathrm{F} / \mathrm{C}$ are likely due to higher nutrient levels. Seed spread of E. curvula is known to occur via wind (for short distances), animals (Halvorson and Guertin, 2003) and also flood water (Nakayama et al., 2007). Considering the timing of seed production and germination, the seasonal flooding in autumn (August-September) could contribute to seed dispersal. It should be noted that sandy subdivisions are subject to seasonal flooding; however, considering the lower frequency of flooding, wind should be considered the main mechanism for seed dispersal.

\section{The effect of shading on growth characteristics}

Subdivisions 207 and 104 contained R. pseudoacacia, which provided shading on the canopies of E. curvula. Subdivision 207 contained greater levels of P2, whereas 104 contained lower levels. Thus, we can conclude that 207 was more sandy, while 104 was more stony in composition. The triplot (Fig. 2) shows this phenomenon very clearly, as they are located further towards the relevant subdivisions. The TNM, TPM, P2 and CaM levels of subdivision 207 are slightly above average, yet lower than the values for the sandy subdivisions. However, as the nutrient level is still above average, it can be regarded as productive in the context of the study area; hence, the competition amongst the species was based on light. Unlike the rest of the sandy subdivisions, the light available in this subdivision was significantly limited, due to shading by $R$. pseudoacacia. Additionally, there were few other species (Figs. 2 and 3). This suggests that E. curvula is capable of competing with other plants under limited light conditions. The colony dimensions (PB, PMAX, HAV and HMAX) were above average, but below those of sandy subdivisions (Fig. 2), suggesting similar competition for light. Nonetheless, the number of colonies was much greater than the number in the sandy subdivisions. These results suggest that the reduced dimensions are a result of intraspecific competition, unlike in sandy areas where competition is with different species (note that in sandy subdivisions E. curvula contributed only $30 \%$ of the total shoot production and species richness was high (Fig. 3)). These arguments are true for subdivision 104, when discussed in the context of stony substrate; however, it could be rather misleading to draw conclusions for the shading effect based on the observations made for only two subdivisions. Matsumoto et al. (2000) studied shading by E. curvula on endangered A. kantoensis and concluded that the impact was negative. They stated that $A$. kantoensis required a relative PPFD of at least $30 \%$ to acclimate successfully during mid-summer. The PPFD and relative PPFD results here are comparable to those noted by Matsumoto et al. (2000).

When the E. curvula cover was greater than $20-30 \%$, the rest of the herbaceous population was noticeably reduced. However, when E. curvula cover was less than $20 \%$, there were still cases in which there was little other herbaceous vegetation. Thus, we cannot make the firm conclusion that the shading of E. curvula has a negative effect on other species; however, it is fair to conclude that shading by $R$. pseudoacacia does not have a negative impact on the abundance of E. curvula. At the same time, the double impact of shading, such as in subdivisions 104 and 207, could inhibit the colonisation of other herbaceous species, as the levels of relative PPFD get very low (e.g., subdivision 207: 0-8\%).

\section{Temporal heterogeneity of $E$. curvula production}

The results of Study A suggest that both stony and sandy substrates promote spatial heterogeneity with respect to the growth characteristics of E. curvula. The same is true for temporal variation with respect to biomass. It should be noted that when two locations differ in their temporal variation, they will induce spatial heterogeneity (Dutilleul, 1993a). Shoot and root production per unit area was more significant in Station 1 than in Station 2, 

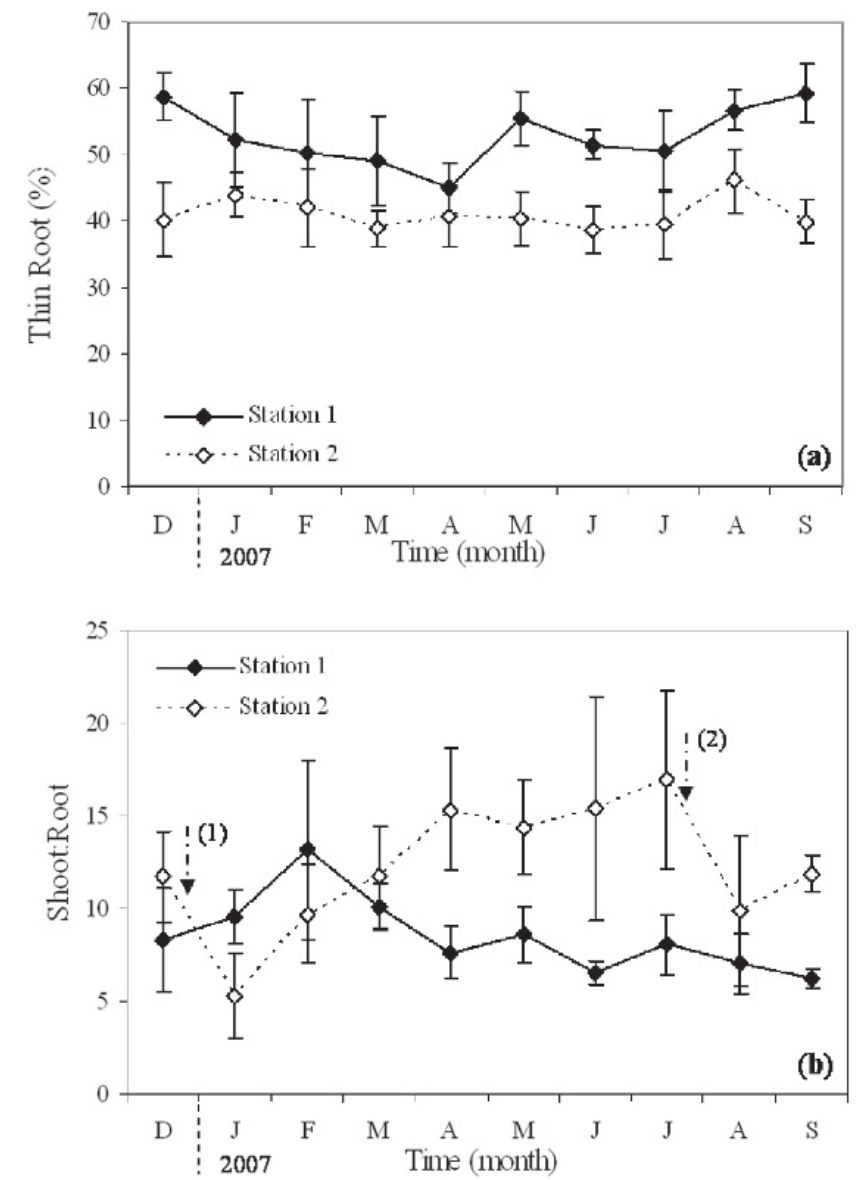

Fig. 7. Temporal variation of (a) thin $\operatorname{root}(\%)$; and (b) shoot to root ratio of Station 1 and Station 2. Vertical arrows (1) and (2) indicate flooding on 17th December 2006 and 15th July 2007.

but shoot production per colony did not show the same trend. However, shoot biomass values for January and August were noticeably lower than the values obtained in the previous months for Station 2. This was due to seasonal flooding on 12th December 2006 and 17th July 2007, which washed away part of the shoots (especially dead sections). In addition, the inundation (duration: 1-2 days) may have inhibited shoot genesis. Eragrostis curvula is tolerant of inundation periods lasting up to five days, and is categorised as a mildly tolerant species (USDA, 2008).

Station 1 had significantly lower soil nutrient levels (Table 4). Thus, biomass production of E. curvula could have been low; however, the biomass data obtained suggest otherwise. Station 2, characterised by high nutrient levels, was a habitat for many herbaceous plants. Thus, intense competition between species inhibited E. curvula production. On the other hand, Station 1 contained few other herbaceous plants. These two distinct phenomena could be the reason for the statistically insignificant trend ( $t$-test, $P>0.05$ ) for shoot biomass among large colonies. The root systems of plants growing in the field were very successful at foraging for nutrients and water in hostile environments where their availability was limited (McCully, 1995). The results of Study B suggest that species in Station 1 produced exceptionally large root

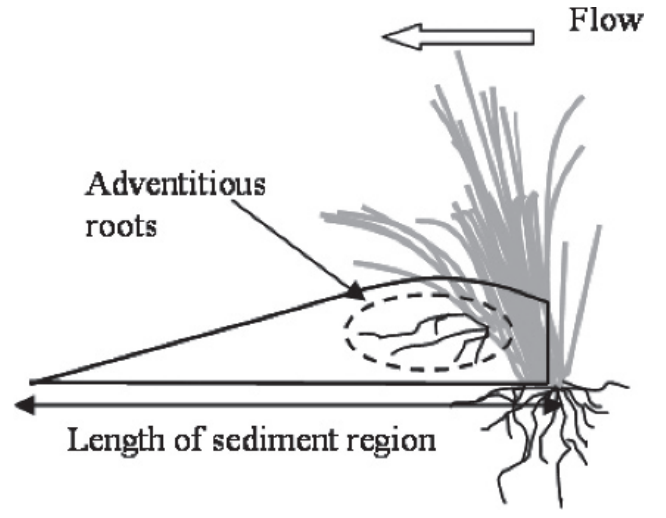

Fig. 8. Typical side view of a sediment bar of an E. curvula colony subject to seasonal flooding.

biomass as a means of acquiring adequate amounts of nutrients and water. In addition to root production, the percentage of thin roots (Fig. 7(a)) was also high for Station 1, and there was a significant difference (t-test, $P<0.05)$ for the months of December, May, June, August and September. As thin roots provide more surface area per unit volume of soil, the nutrient acquisition is further enhanced (Lamont, 2003). These conclusions, based on temporal trends, are comparable with the results of Study A. These findings demonstrate E. curvula's ability to adapt to different soil conditions by way of selective placement of biomass and root plasticity.

A number of empirical findings support the idea that resource availability influences biomass allocation (Asaeda et al., 2008; Meimei et al., 2008), and it has been shown that nutrient availability affects the degree of root to shoot biomass partitioning for some annual plant species (Asaeda et al., 2008). In the present study, the biomass allocation to roots is obviously high with the low nutrient availability in Station 1 (Fig. 7(b)). Only the months of January and February showed low shoot to root ratios for Station 2 relative to Station 1. This in turn can be attributed to shoots being torn-off by currents during the December flooding. The ordination results (Fig. 2) also suggest that Station 2 (i.e. sandy subdivisions) has higher values for shoot to root (S/R) ratios than Station 1 (i.e. extremely stony subdivisions). It should be noted that subdivisions 310 and 311 , which had stony substrate, also had high $\mathrm{S} / \mathrm{R}$ ratios, similar to those found in the sandy subdivisions (Fig. 2 indicates this to be above average). This is due to the fine sand and silt accumulated by E. curvula, which consequently makes its local habitat rather sandy. Though it was found that there were significantly fewer $E$. curvula colonies in subdivisions near the river, the localised sand that accumulated was noticeably high. Figure 8 illustrates a typical view of sand accumulation.

\section{Comparison with past reports on biomass production}

The shoot biomass of Station 1 reached a maximum of 2108 DW g.m ${ }^{-2}\left(21079 \mathrm{~kg} \cdot \mathrm{ha}^{-1}\right)$ in April, whereas 

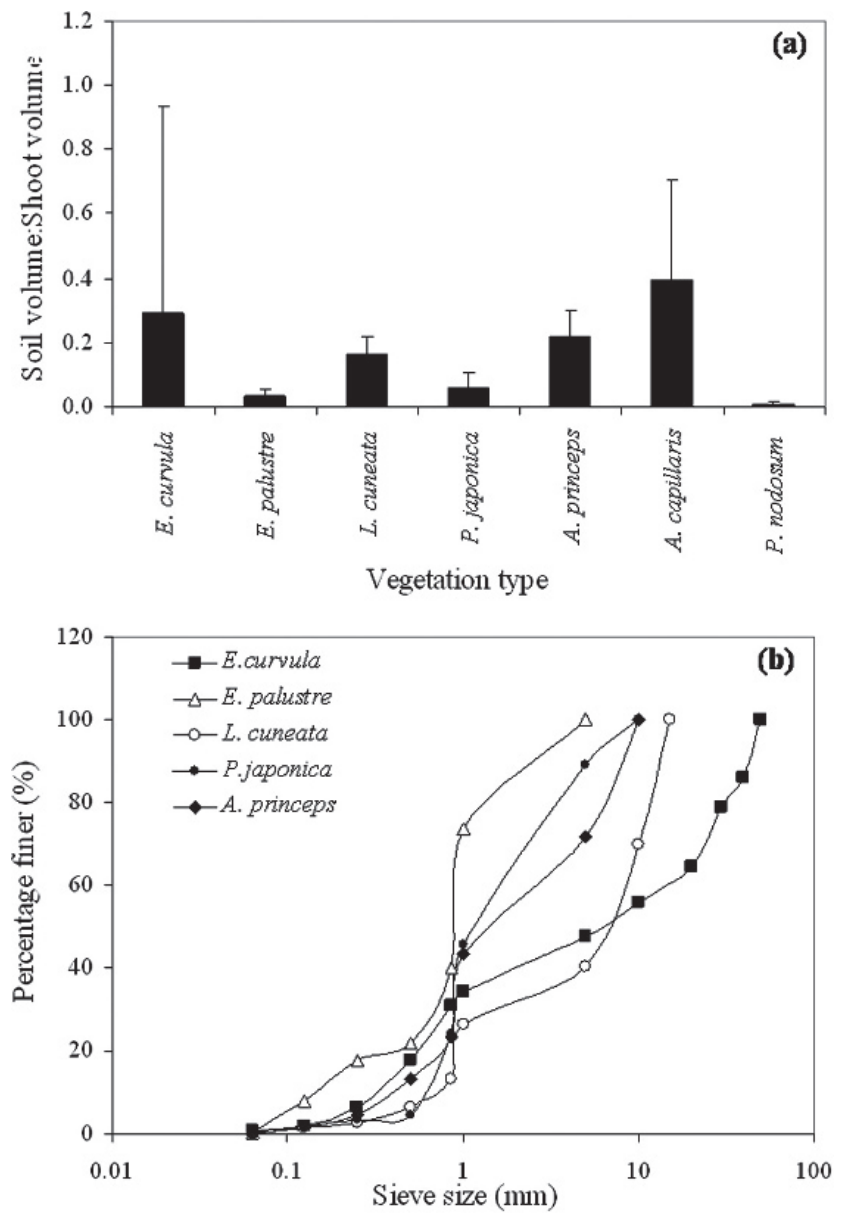

Fig. 9. (a) Ratio of volume of sediment accumulated to above ground bulk volume of plants; and (b) particle size distribution of sediment accumulated for different species.

the root biomass reached a maximum of 248 DW g.m ${ }^{-2}$ ( $2477 \mathrm{~kg} \cdot \mathrm{ha}^{-1}$ ) in August. The shoot and root production of E. curvula in past studies falls within a wide range of values. Montani et al. (1996) reported the production to be $6418 \mathrm{~kg} \cdot \mathrm{ha}^{-1}$ and $11200 \mathrm{~kg} \cdot \mathrm{ha}^{-1}$, respectively, for the shoots and roots of a semi-arid grassland in Argentina. Some reports (Tropical Forages ${ }^{\mathcal{C}}$ ) detail the shoot production to be $2721-9070 \mathrm{~kg} . \mathrm{ha}^{-1}$ for infertile soils and 18 140-27 $210 \mathrm{~kg} . \mathrm{ha}^{-1}$ for irrigated soils. Similar values were reported by Roberts and Carbon (1969). Considering the very low root biomass values and comparatively high shoot biomass values, it seems that the flood meadow under consideration contains abundant nutrients for E. curvula colonization, probably because the meadow experienced forestation as recently as 15 years ago (MLIT, 2000).

\section{Contribution of $E$. curvula to soil conservation}

Figure 9(a) illustrates the ratio of sand volume accumulated to the aboveground bulk volume of plants for different herbaceous species (all samples were taken from areas with the same flood impact). According to Figure 9(a), it is obvious that A. capillaris and E. curvula have the highest potential for sediment trapping. When considering the particle size distribution of the trapped sediment of different species (Fig. 9(b)), species like L. cuneata, E. palustre, $P$. japonica and $A$. princeps accumulate relatively fine sediments. However, in the case of E. curvula, the well-graded curves suggest that it is trapping sediments with a wide range of particle sizes. Furthermore, the sediment bars of E. curvula were obviously large in size, allowing other species to colonize on the accumulated sediment (data not shown). The ability of E. curvula to accumulate sediment (sand) leads to changes in the microtopography of gravely flood plains.

\section{The effect of dam construction and management on E. curvula}

In a steeply sloping river, such as the one in this study, the construction of upstream dams stops sediment flow, except for the wash load. This gradually coarsens the downstream active channels, sediment bars and flood meadows. This leads to reduced water retention, as well as reduced nutrient availability. Consequently, stress tolerant species like E. curvula will eventually colonize these areas, making the dam construction a contributing factor. However, it should be noted that high nutrient levels have been shown to promote non-native plants (Barger et al., 2003), contrary to the findings of our study. On the other hand, the development of E. curvula does have positive outcomes for the less productive downstream channel areas. Its development provides much needed cover for the bare land, which is prone to soil erosion, especially by the wind. The dead clump at the centre of a colony, along with the plant litter, traps the limited nutrients in the system. Furthermore, colonies close to the river accumulate the wash load sediment and the sediment from tributaries that are not subject to water manipulation during seasonal flooding.

Sediment release by dams has been practised as a mitigating method in water manipulation (Bravard et al., 1999; MLIT, 2000). Artificial sediment release has been practised in many Japanese rivers, such as Kurobe River, which witnessed its first sediment release in 1991 (Tazaki et al., 2003). The main objective of sediment release is to prevent riverbed incision and to regain reservoir capacity. However, due to the accumulation of fine sediment in active river channel areas, this might enhance vegetation (Asaeda et al., 2008). According to our findings, this can result in the succession of herbaceous species that require high moisture and nutrients, over the development of E. curvula.

\section{Conclusions}

Although the abundance of E. curvula changed under various environmental scenarios, it showed significant levels of adaptation to its micro-environments by way of biomass allocation and root morphological plasticity, 
apart from selective colonisation. Eragrostis curvula seemed to be prominent in areas where conditions were less favourable for plant growth. Areas that contained more gravel, lower nutrient levels, reduced soil moisture and even less light were found to be ideal breeding grounds for E. curvula. The opposite was noted when the conditions were favourable. Therefore, E. curvula proved to be a weak competitor in areas with sandy soil and high levels of nutrients and moisture. These findings concur with the model developed by Grime (1979), who stated that stress-tolerant plants are poor competitors under stress-free conditions. River regulation aided the collection of gravel downstream, creating conditions for the intensified colonisation of E. curvula. Considering the capacity of E. curvula to exist in environments with substandard soil conditions, this plant will contribute to soil conservation and forestation processes in the downstream areas of regulated rivers.

Acknowledgements. The authors would like to thank Prof. Takeshi Fujino and Dr. Lalith Rajapakse for their help. We deeply appreciated the comments provided by two anonymous reviewers. This research was financially supported by a Research Grant-in-Aid from the Japanese Ministry of Education, Culture, Sports, Science and Technology.

\section{References}

APHA (American Public Health Association)/American Water Works Association/Water Environment Federation, 1998. Standard Methods for the Examination of Water and Wastewater, 20th edn., Washington D.C.

Asaeda T. and Ca V.T., 1993. The subsurface transport of heat and moisture and its effect on the environment: A numerical model. Boundary-Layer Meteorol., 65, 159-179.

Asaeda T. and Hung L.Q., 2007. Internal heterogeneity of ramet and flower densities of Typha angustifolia near the boundary of the stand. Wetl. Ecol. Manag., 15, 155-164.

Asaeda T. and Rajapakse L., 2008. Effects of spates of different magnitudes on a Phragmites japonica population on a sandbar of a frequently disturbed river. River Res. Appl., 24, $1310-1324$.

Asaeda T., Hai D.N., Manatunge J., Williams D. and Roberts J., 2005. Latitudinal characteristics of below- and above-ground biomass of Typha: a modelling approach. Ann. Bot., 96, 299-312.

Asaeda T., Siong K., Kawashima T. and Sakamoto K., 2008. Growth of Phragmites japonica on a sandbar of a regulated river: morphological adaptation of the plant to low water and nutrient availability in the substrate. River Res. Appl., doi:10.1002/rra.1191.

ASTM (American Society for Testing and Materials), 2002. Standard Test Methods for Sieve Analysis and Water Content of Refractory Materials, C92-C95.

Austin A.T., Yahdjian L., Stark J.M., Belnap J., Porporato A., Norton U., Ravetta D.A. and Scaeffer S.M., 2004. Water pulses and biogeochemical cycles in arid and semiarid ecosystems. Oecologia, 141, 221-235.
Azami K., Suzuki H. and Toki S., 2004. Changes in riparian vegetation communities below a large dam in a monsoonal region: Futase dam, Japan. River Res. Appl., 20, 549-563.

Barger N.N., D'Antonio C.M.D., Ghneim T. and Cuevas E., 2003. Constraints to colonization and growth of the African grass, Melinis minutiflora, in a Venezuelan savanna. Plant Ecol., 167, 31-43.

Bravard J.-P., Landon N., Peiry J.-L. and Piégay H., 1999. Principles of engineering geomorphology for managing channel erosion and beadload transport, examples from French rivers. Geomorphology, 31, 291-311.

Brunet R.-C. and Astin K.B., 2000. A 12-month sediment and nutrient budget in a floodplain reach of the River Adour, southwest France. River Res. Appl., 16, 267-277.

Clifford P., Richardson S. and Hémon D., 1989. Assessing the significance of the correlation between two spatial processes. Biometrics, 45, 123-134.

Colom M.R. and Vazzana C., 2002. Water stress effects on three cultivars of Eragrostis curvula. Ital. J. Agron., 6, 127132.

Dillaha T.A., Reneau R.B., Mostanghimi S. and Lee D., 1989. Vegetative filter strips for agricultural non point source pollution control. Trans. Am. Soc. Agr. Eng., 32, 513-519.

Dutilleul P., 1993a. Spatial heterogeneity and the design of ecological field experiments. Ecology, 74, 1646-1658.

Dutilleul P., 1993b. Modifying the $t$ test for assessing the correlation between two spatial processes. Biometrics, 49, 305-314.

Gatsuk L.E., Smirnova O.V., Vorontzova L.I., Zaugolnova L.B. and Zhukova L.A., 1980. Age status of plants of various growth forms: A review. J. Ecol., 67, 21-33.

Goodall D.W., 1970. Statistical plant ecology. Annu. Rev. Ecol. Syst., 1, 99-124.

Grime J.P., 1979. Plant Strategies and Vegetation Processes, John Wiley and Son, Chichester.

Halvorson W.L. and Guertin P., 2003. USGS Weeds in the West project: Status of introduced plants in southern Arizona parks, Plant Fact Sheets prepared for Tuzigoot National Monument, Tucson, AZ: U.S. Geological Survey, http:// sdrsnet.srnr.arizona.edu/index.php?page $=$ datamenu\&lib $=$ $2 \&$ sublib $=13$.

Harris R.R., Fox C.A. and Risser R., 1987. Impacts of hydroelectric development on riparian vegetation in the Sierra Nevada region, California, USA. Environ. Manage., 11, 519-527.

Islam A.K.M.S., Asher C.J. and Edwards D.G., 1987. Response of plants to calcium concentration in flowing solution culture with chloride or sulphate as the counter-ion. Plant. Soil., 98, 377-395.

Jongman R.H.G., Ter Braak C.J.F. and Van Tongeren O.F.R., 1987. Data Analysis in Community and Landscape Ecology, Cambridge University Press, New York.

Kuo S., 1996. Phosphorus. In: Methods of Soil Analysis: Chemical Methods, Part III, Sparks D.L. (ed.), ASA and SSSA: Madison, USA, 869-919.

Lamont B.B., 2003. Structure, ecology and physiology of root clusters - A review. Plant Soil, 248, 1-19.

Loneragan J.F. and Snowball K., 1969. Calcium requirements of plants. Aust. J. Agric. Res., 20, 465-478.

Matsumoto J., Muraoka H. and Washitani I., 2000. Whole plant carbon gain of an endangered herbaceous species Aster 
kantoensis and the influence of shading by an alien grass Eragrostis curvula in its gravelly floodplain habitat. Ann. Bot., 86, 787-797.

McCully M., 1995. How do real roots work? Some new views of root structure. Plant Physiol., 109, 1-6.

Meimei C., Baodong C. and Petra M., 2008. Plant growth and soil microbial community structure of legumes and grasses grown in monoculture or mixture. J. Environ. Sci., 20, 12311237.

Mengel K. and Kirkby E.A., 2001. Principles of Plant Nutrition, 5th edn., Kluwer Academic Publishers, Dordrecht.

MLIT, 2000. Arakawa basin environmental impact assessment report, Arakawa Upstream Office, Ministry of Land, Infrastructure and Transport Japan (in Japanese).

Montani T., Busso C.A., Fernandez O.A. and Brevedan R.E., 1996. Production and nitrogen cycling in an ecosystem of Eragrostis curvula in semi arid Argentina I. Plant biomass productivity. Acta. Oecol., 17, 151-162.

Murphy J. and Riley J.P., 1962. A modified single solution method for the determination of phosphate in natural waters. Anal. Chim. Acta., 27, 31-36.

Nakayama N., Nishihiro J., Kayaba Y., Muranaka T. and Washitani I., 2007. Seed deposition of Eragrostis curvula, an invasive alien plant on a river floodplain. Ecol. Res., 22, 696-701.

Osem Y., Perevolotsky A. and Kigel J., 2002. Grazing effect on diversity of annual plant communities in a semiarid rangeland: interactions with small-scale spatial and temporal variation in primary productivity. J. Ecol., 90, 936-946.

Reith J.W.S., Inkson R.H.E., Scott N.M., Caldwell K.S., Ross J.A.M. and Simpson W.E., 1987. Estimates of soil phosphorus for different soil series. Fert. Res., 11, 123-142.

Roberts F.J. and Carbon B.A., 1969. Growth of tropical and temperate grasses and legumes under irrigation in southwest Australia. Trop. Grassl., 3, 109-116.

Schulze E.-D., 2000. The Carbon and Nitrogen Cycle of Forest Ecosystems. In: Caldwell M.M., Heldmaier G., Lange O.L., Mooney H.A., Schulze E.-D. and Sommer U. (eds.), Carbon and Nitrogen Cycling in European Forest Ecosystems,
Ecological Studies, Volume 142, Springer, Heidelberg, Germany, 3-13.

Sharma P., Asaeda T. and Fujino T., 2007. Effect of water depth on the rhizome dynamics of Typha angustifolia. Wetl. Ecol. Manag., 16, 43-49.

Sigler W.V. and Turco R.F., 2002. The impact of chlorothalonil application on soil bacterial and fungal populations as assessed by denaturing gradient gel electrophoresis. Appl. Soil. Ecol., 21, 107-118.

Steiger J. and Gurnell A.M., 2002. Spatial hydrogeomorphological influences on sediment and nutrient in riparian zones: observation from the Garonne River, France. Geomorpho$\log y, 49,1-23$.

Steiger J., Tabacchi E., Dufour S., Corenblit D. and Peiry J.-L., 2005. Hydrogeomorphic processes affecting riparian habitat within alluvial channel-floodplain river systems: A review for the temperate zone. River Res. Appl., 21, 719-737.

Tazaki K., Sato M., van der Gaast S. and Morikawa T., 2003. Effects of clay-rich river-dam sediments on downstream fish and plant life. Clay Miner., 38, 243-253.

Ter Braak C.J.F. and Smilauer P., 2002. CANOCO Reference Manual and CanoDraw for Windows User's Guide: Software for Canonical Community Ordination (version 4.5), Microcomputer Power (Ithaca), New York.

Tropical Forages: an interactive selection tool, http://www. tropicalforages.info/index.htm.

USEPA (United States Environmental Protection Agency), Digestion method 3050B, acid digestion of sediments and soils SW-846, http://www.epa.gov/SW-846/pdfs/3050b.pdf.

USDA (United States Department of Agriculture), 2008. Natural Resources Conservation Service (NRCS), http://plants.usda.gov.

Van Oorschot M., Hayes C. and Van Strien I., 1998. The influence of soil desiccation on plant production, nutrient uptake and plant nutrient availability in two French floodplain grasslands. River Res. Appl., 14, 313-327.

Wan C. and Sosebee R.E., 2000. Central dieback of the dryland bunchgrass Eragrostis curvula (weeping lovegrass) re-examined: The experimental clearance of tussock centres. J. Arid Environ., 46, 69-78. 